Preface

\title{
Clinical Scoring Systems in Thrombosis and Hemostasis
}

\author{
Adam Cuker, MD, MS ${ }^{1,2}$ \\ ${ }^{1}$ Department of Medicine, Perelman School of Medicine, University of \\ Pennsylvania, Philadelphia, Pennsylvania \\ ${ }^{2}$ Department of Pathology and Laboratory Medicine, Perelman \\ School of Medicine, University of Pennsylvania, Philadelphia, \\ Pennsylvania
}

Semin Thromb Hemost 2017;43:447-448.

Welcome to this special theme issue of Seminars in Thrombosis $\mathcal{E}$ Hemostasis on "clinical scoring systems in thrombosis and hemostasis." Clinical scoring systems (CSSs) are known by many other names including clinical prediction rules, clinical decision rules, probability assessments, prediction models, and risk scores. ${ }^{1}$ No matter which term is used, CSSs are tools that quantify the individual contributions that various components of the history, physical examination, and basic laboratory investigation make toward a patient's diagnosis or prognosis. ${ }^{2}$ Although CSSs may be used as research tools (e.g., as a means of defining whether subjects have a disease of interest or quantifying their risk of a certain outcome), they are first and foremost intended to improve clinical care by standardizing, simplifying, and improving the accuracy of clinicians' diagnostic or prognostic assessments.

Development of CSSs includes four key steps: (1) derivation, (2) validation, (3) impact analysis, and (4) implementation. ${ }^{1,2}$ In the derivation step, a comprehensive list of items from the history, physical examination, and basic investigation with potential predictive power is constructed. A group of patients (the derivation cohort) is studied to determine whether the candidate variables predict the outcome of interest. Statistical analysis reveals which predictors are most powerful and should be included in the CSS and which may be omitted without loss of predictive power. In the second step, the performance of the CSS must be validated in a separate population (the validation cohort). The most useful CSSs perform well not only in populations similar to the derivation cohort but also in broad clinical settings with a varying prevalence of the outcome of interest. After a CSS has been validated, its use must be shown to change clinician behavior and improve patient outcomes and/or reduce costs compared with standard of care. Typical study designs used for such impact analyses include randomization of administrative units to the application or nonapplication of the CSS or pre- versus postimplementation studies. Even if a CSS is

Address for correspondence Issue Theme Clinical Scoring Adam Cuker, MD, MS, Hospital of Systems in Thrombosis and the University of Pennsylvania, Hemostasis; Guest Editor: Adam 3400 Spruce Street, Philadelphia, Cuker, MD, MS.

PA 19104

(e-mail: adam.cuker@uphs.

upenn.edu).

shown to have a favorable effect on patient outcomes or resource utilization in an impact analysis, there is no guarantee that practitioners will adopt it. Several potential barriers to the adoption of CSSs exist. Clinicians may be unaware of the existence of a CSS, or CSSs may be complex, cumbersome to use, or hard to remember. Or clinicians may distrust a CSS when it conflicts with their clinical judgment. As such, the final step in the development of a CSS is to evaluate whether it has been accepted and adopted in realworld clinical practice. Many CSSs have been derived and validated (steps 1 and 2), but comparatively, few have been tested in an impact analysis or enjoyed widespread adoption (steps 3 and 4). ${ }^{1,2}$

The number of published CSSs has grown tremendously in recent years. A Medline search by Toll et al found that the number of articles on CSSs more than doubled between 1995 and $2005(6,744$ vs. 15,662$) .^{3}$ A recent systematic review identified 434 unique CSSs pertinent to primary care alone. ${ }^{4}$ Some CSSs such as APACHE (Acute Physiology and Chronic Health Evaluation) II, the MELD (Model of End-Stage Liver Disease) score, Pneumonia Severity Index, Ranson criteria, and Glasgow Coma Scale have become part of the daily lexicon in hospital wards and clinics throughout the world. ${ }^{5-9}$ However, the sheer number of CSSs available to clinicians is both potentially helpful and inhibitory for their adoption.

The field of thrombosis and hemostasis has not been immune to the proliferation of CSSs. This theme issue includes 12 articles on the application of CSSs to various disorders of bleeding and clotting. Each article reviews available CSSs, where they stand in the four-step development process, their strengths and limitations, and their applicability (real or potential) to clinical practice.

Several articles are devoted to the use of CSSs for venous thromboembolism (VTE). The first three articles focus on CSSs for estimating the risk of VTE in surgical patients, ${ }^{10}$

Copyright $\odot 2017$ by Thieme Medical Publishers, Inc., 333 Seventh Avenue, New York, NY 10001, USA. Tel: +1(212) 584-4662.
DOI https://doi.org/ 10.1055/s-0037-1602661. ISSN 0094-6176. 
hospitalized medical patients, ${ }^{11}$ and patients with cancer. ${ }^{12}$ The next article summarizes the role of CSSs in diagnostic pathways for VTE. ${ }^{13}$ CSSs have also been developed to inform key management issues in VTE. Prognostic CSSs for acute pulmonary embolism may be used to determine whether a patient is appropriate for outpatient therapy. ${ }^{14}$ CSSs for estimating the risk of recurrent VTE may be used to guide decisions regarding the duration of anticoagulation. ${ }^{15}$ Finally, CSSs have been developed for diagnosis of postthrombotic syndrome, a common complication of deep vein thrombosis. ${ }^{16}$

VTE is not the only thrombotic disorder to which CSSs may be applied. CSSs are widely used for estimating stroke risk in patients with atrial fibrillation. ${ }^{17}$ The potential benefit of anticoagulation to reduce stroke risk in patients with atrial fibrillation must be balanced against the potential harms of bleeding. Several CSSs have been developed to estimate the risk of anticoagulant-associated bleeding. ${ }^{18}$ Another article in this issue focuses not on a specific disorder but on a specific predictive variable, $\mathrm{ABO}$ blood type, and its role in CSSs for thrombotic disorders. ${ }^{19}$

CSSs have a lesser but nonetheless growing presence in the diagnosis of bleeding and platelet disorders. Bleeding scores are an important research tool and have now entered the clinic as a means of identifying patients with possible bleeding disorders (e.g., von Willebrand disease). ${ }^{20}$ Recent work has also led to development of CSSs intended to aid in differentiating thrombotic thrombocytopenic purpura from other forms of thrombotic microangiopathy. ${ }^{21}$

As CSSs continue to permeate the medical literature and clinical practice in thrombosis and hemostasis, it is hoped that readers find this special theme issue timely, informative, and enjoyable.

\section{Disclosure}

A.C. has served as a consultant for Biogen-Idec, Diagnostica Stago, and Genzyme and has received research support from Biogen-Idec, Spark Therapeutics, and T2 Biosystems.

\section{References}

1 Adams ST, Leveson SH. Clinical prediction rules. BMJ 2012;344: d8312

2 McGinn TG, Guyatt GH, Wyer PC, Naylor CD, Stiell IG, Richardson WS; Evidence-Based Medicine Working Group. Users' guides to the medical literature: XXII: how to use articles about clinical decision rules. JAMA 2000;284(01):79-84

3 Toll DB, Janssen KJ, Vergouwe Y, Moons KG. Validation, updating and impact of clinical prediction rules: a review. J Clin Epidemiol 2008;61(11):1085-1094

4 Keogh C, Wallace E, O'Brien KK, et al. Developing an international register of clinical prediction rules for use in primary care: a descriptive analysis. Ann Fam Med 2014;12(04):359-366

5 Knaus WA, Draper EA, Wagner DP, Zimmerman JE. APACHE II: a severity of disease classification system. Crit Care Med 1985; 13(10):818-829

6 Kamath PS, Wiesner RH, Malinchoc M, et al. A model to predict survival in patients with end-stage liver disease. Hepatology 2001;33(02):464-470

7 Ranson JH, Rifkind KM, Roses DF, Fink SD, Eng K, Spencer FC. Prognostic signs and the role of operative management in acute pancreatitis. Surg Gynecol Obstet 1974;139(01):69-81

8 Fine MJ, Auble TE, Yealy DM, et al. A prediction rule to identify low-risk patients with community-acquired pneumonia. $\mathrm{N}$ Engl J Med 1997;336(04):243-250

9 Teasdale G, Jennett B. Assessment of coma and impaired consciousness. A practical scale. Lancet 1974;2(7872):81-84

10 Jacobs B, Pannucci C. Scoring systems for estimating risk of venous thromboembolism in surgical patients. Semin Thromb Hemost 2017;43(05):449-459

11 Barbar S, Prandoni P. Scoring systems for estimating risk of venous thromboembolism in hospitalized medical patients. Semin Thromb Hemost 2017;43(05):460-468

12 Angelini D, Khorana AA. Risk assessment scores for cancerassociated venous thromboembolic disease. Semin Thromb Hemost 2017;43(05):469-478

13 Le Gal G, Righini M, Wells PS. Scoring systems for diagnosis of acute venous thromboembolism. Semin Thromb Hemost 2017; 43(05):479-485

14 Morillo R, Moores L, Jiménez D. Prognostic scores for acute pulmonary embolism. Semin Thromb Hemost 2017;43(05):486-492

15 Nichele I, Tosetto A. Scoring systems for estimating the risk of recurrent venous thromboembolism. Semin Thromb Hemost 2017;43(05):493-499

16 Skuterud Wik H, Ghanima W, Morten Sandset P, Kahn SR. Scoring systems for postthrombotic syndrome. Semin Thromb Hemost 2017;43(05):500-504

17 Shahid F, Lip GYH. Risk stratification models in atrial fibrillation. Semin Thromb Hemost 2017;43(05):505-513

18 Parks AL, Fang MC. Scoring systems for estimating the risk of anticoagulant-associated bleeding. Semin Thromb Hemost 2017; 43(05):514-524

19 Franchini M, Marano G, Vaglio S, Catalano L, Pupella S, Liumbruno $\mathrm{GM}$. The role of $\mathrm{ABO}$ blood type in thrombosis scoring systems. Semin Thromb Hemost 2017;43(05):525-529

20 Bowman ML, James PD. Bleeding scores for the diagnosis of von Willebrand disease. Semin Thromb Hemost 2017;43(05):530-539

21 Bendapudi PK, Upadhyay V, Sun L, Marques MB, Makar RS. Clinical scoring systems in thrombotic microangiopathies. Semin Thromb Hemost 2017;43(05):540-548 